\title{
DENTRO DO ESPELHO DE SUZY LEE
}

\author{
Luis Carlos Girão
}

Submetido em 26 de maio de 2018.

Aceito para publicação em 27 de agosto de 2018.

Cadernos do IL, Porto Alegre, n. ${ }^{\circ}$ 57, novembro de 2018. p. 247- 259

\section{POLÍTICA DE DIREITO AUTORAL}

Autores que publicam nesta revista concordam com os seguintes termos:

(a) Os autores mantêm os direitos autorais e concedem à revista o direito de primeira publicação, com o trabalho simultaneamente licenciado sob a Creative Commons Attribution License, permitindo o compartilhamento do trabalho com reconhecimento da autoria do trabalho e publicação inicial nesta revista.

(b) Os autores têm autorização para assumir contratos adicionais separadamente, para distribuição não exclusiva da versão do trabalho publicada nesta revista (ex.: publicar em repositório institucional ou como capítulo de livro), com reconhecimento de autoria e publicação inicial nesta revista.

(c) Os autores têm permissão e são estimulados a publicar e distribuir seu trabalho online (ex.: em repositórios institucionais ou na sua página pessoal) a qualquer ponto antes ou durante o processo editorial, já que isso pode gerar alterações produtivas, bem como aumentar o impacto e a citação do trabalho publicado.

(d) Os autores estão conscientes de que a revista não se responsabiliza pela solicitação ou pelo pagamento de direitos autorais referentes às imagens incorporadas ao artigo. A obtenção de autorização para a publicação de imagens, de autoria do próprio autor do artigo ou de terceiros, é de responsabilidade do autor. Por esta razão, para todos os artigos que contenham imagens, o autor deve ter uma autorização do uso da imagem, sem qualquer ônus financeiro para os Cadernos do IL.

\section{POLÍTICA DE ACESSO LIVRE}

Esta revista oferece acesso livre imediato ao seu conteúdo, seguindo o princípio de que disponibilizar gratuitamente o conhecimento científico ao público proporciona sua democratização.

http://seer.ufrgs.br/cadernosdoil/index

Quinta-feira, 22 de novembro de 2018. 


\title{
DENTRO DO ESPELHO DE SUZY LEE
}

\author{
INSIDE THE MIRROR OF SUZY LEE
}

Luis Carlos Girão*

\begin{abstract}
RESUMO: Este artigo apresenta uma análise comparativa do aspecto específico relacionado ao processo de figurabilidade resultante dos movimentos de aparecimento e desaparecimento presentes no livro-imagem Espelho (2009), de Suzy Lee, em paralelo ao aclamado "atlas de imagens" do historiador da arte Aby Warburg, Mnemosyne (1929). Nesse percurso, discutimos brevemente os sintomas da produção de presença nas páginas em branco que apontam a existência de um terceiro "cenário" nesta narrativa pictórica criada pela artista sul-coreana. Para tanto, propomos diálogos com os escritos de Michaud (2013) sobre o trabalho de Warburg; os pensamentos de Gumbrecht (2010) sobre a produção de presença na linguagem; além de visadas nas reflexões de Flusser (2008) e Benjamin (1987), bem como de Nodelman (1988) e Linden (2011).
\end{abstract}

PALAVRAS-CHAVES: aparecimento; desaparecimento; figurabilidade; narrativa pictórica.

ABSTRACT: This article presents a comparative analysis of the specific aspect related to the process of figurability resultant from the movements of appearance and disappearance present in the picture-book Mirror (2009), by Suzy Lee, in parallel to the acclaimed "atlas of images" from the art historian Aby Warburg, Mnemosyne (1929). In this course, we briefly discuss the symptoms of the production of presence in the blank pages that points out the existence of a third "scenario" in this pictorial narrative. For this purpose, dialogues were conducted with the writings of Michaud (2013) on Warburg's work; the thoughts of Gumbrecht (2010) on the production of presence; as well as some points of view from Flusser (2008), Benjamin (1987), Nodelman (1988), and Linden (2011).

KEYWORDS: appearance; disappearance; figurability; pictorial narrative.

Em meio aos estudos realizados sobre o objeto livro no mercado da Literatura Infantil desde as décadas de 1960 e 1970, uma vertente que vem ganhando destaque entre pesquisadores das mais diversas áreas - Artes Plásticas, Comunicação, Educação, Design Gráfico, Psicologia etc. - é aquela que se debruça sobre os ditos livros-imagem, ainda um território fértil, porém, pouco explorados academicamente.

O diferencial apresentado pelos livros-imagens está no fato de eles serem constituídos, essencialmente, em linguagem visual - da fotografia às ilustrações -, ficando o texto verbal, muitas vezes, resumido ao título impresso nas capas, ou mesmo em rápidas passagens no decorrer das páginas internas. Segundo a tipologia designada por Torben Gregersen (apud NIKOLAJEVA \& SCOTT, 2011), as obras impressas compreendidas como "livros-imagem" são aquelas compostas por narrativas pictóricas, ou seja, sem ou com pouquíssimas palavras.

Um dos nomes de maior destaque internacional na produção contemporânea de livros-imagem é o da book artist sul-coreana Suzy Lee, cuja primeira publicação literária, em 2002, foi uma versão em imagens para o clássico de Lewis Carroll, Alice In Wonderland, mesclando fotografias, teatro, obras de arte clássicas e ilustrações. Com a repercussão de seu trabalho na Europa e na Ásia, a artista plástica foi convidada a lançar Mirror (2003) pela editora italiana Corraini Edizioni que, por anos, se encarregou dos livros do renomado designer Bruno Munari. O livro foi publicado no Brasil pela Cosac

\footnotetext{
* Doutorando em Literatura e Crítica Literária pela Pontifícia Universidade Católica de São Paulo (PUC/SP), com bolsa FAPESP (Proc. 2018/10575-4); membro do Grupo de Pesquisa (CNPq) "A voz escrita infantil e juvenil: práticas discursivas". E-mail: luis.changmin@ gmail.com.
} 
Naify como Espelho (2009) - primeiro título de sua consagrada “Trilogia da Margem", composta também por Onda (2008) e Sombra (2010).

Em formato retangular vertical, Espelho assemelha-se à forma padrão de espelhos, o que restringe seu campo de exposição - logo, de ação - nos acontecimentos narrados visualmente. Mesclando as técnicas do carvão, para um traçado sinuoso e dinâmico da garotinha, e de tinta acrílica em tons de preto e amarelo, emanando a decalcomania, essa narrativa pictórica traz para o centro do objeto livro o embate vivido entre uma garotinha que habita as páginas pares (à esquerda), compreendidas como "mundo real" ou "primeiro cenário", e seu reflexo projetado nas páginas ímpares (à direita), compreendidas enquanto "mundo da fantasia" ou "segundo cenário". Todo o drama inscrito nas duplas abertas é movimentado pelo ir e vir do virar de páginas, nas buscas por ações e reações dos dois cenários entre si e em sua relação com um "terceiro cenário": a margem central do livro. Isso posto, perguntaríamos: de que modo essa movimentação no entrepáginas, de uma dupla à outra, vai afetando a narrativa?

Bem antes disso, em meio aos muitos historiadores da arte que vinham estudando como se estruturam as imagens plásticas na produção artística entre final do século XIX e começo do século XX, o nome do alemão Aby Warburg se destaca pela sua forma inédita, além de peculiar, de contar visualmente as histórias da arte inscritas ao longo de anos.

O apelidado "atlas de imagens" de Warburg, intitulado Mnemosyne (1929) - que significa "memória" (WARBURG apud MICHAUD, 2013, p. 39) - expõe a visão do teórico cultural germânico acerca de uma "iconologia dos intervalos" (MICHAUD, 2013, p. 295), entendimento pelo qual ele associa imagens e textos dispostos em placas de tecido preto dentro de sua biblioteca particular - atualmente o Warburg Institute, localizado em Londres. Este caráter expositivo do Mnemosyne cria uma dinâmica distinta quanto à leitura visual dos conteúdos abordados em cada uma de suas placas.

As exposições teóricas/pictóricas de Warburg vão de encontro a algumas características presentes nas exposições narrativas/pictóricas feitas ao longo das páginas duplas que compõem o livro-imagem de Suzy Lee. Para realizar a análise aqui proposta, entramos em contato com os escritos do crítico e teórico visual Philippe-Alain Michaud (2013) sobre a obra de Warburg, no referente aos movimentos presentes nas imagens, para identificar e elencar aspectos que estruturam visualmente o Mnemosyne enquanto história exposta e que se refletem na constituição de Espelho enquanto narrativa à mostra. Além disso, buscamos nas reflexões do crítico e teórico das artes Hans Ulrich Gumbrecht (2010), no que se refere aos sintomas e à produção de presença na linguagem, aspectos que influenciam a criação de significações nos espaços entre inscrições visuais.

Convidando o leitor a "entrar" no livro, a própria Suzy Lee expressa em seu primeiro ensaio teórico: "Parece que os livros-imagem dizem: 'Eu vou mostrar pra você. Apenas sinta"” (LEE, 2012, p. 148). Tal sentimento convidativo também se faz presente nas placas temáticas do atlas warburgiano, para o olhante de história da arte. Além disso, esse mesmo convite dialoga com o argumento de Gumbrecht (2010) acerca da presentificação, ou seja, a possibilidade de "falar" ou "tocar" com o que está escondido, em nosso caso, nas páginas em branco, "vazias", de Espelho.

\section{Figurabilidade na narrativa pictórica}

Apesar de não ter concluído seu tão comentado e prestigiado "atlas de imagens", Aby Warburg conseguiu um grande feito para a história da arte contemporânea ao idealizar e elaborar o Mnemosyne entre 1927 e 1929. As 63 placas de tecido preto, onde 
foram expostas imagens das mais variadas origens - reproduções de obras de arte, recortes de documentos e jornais, anotações etc. -, formam "pequenos mundos encerrados em um quadrilátero", à semelhança do que reflete Suzy Lee (2012, p. 178) sobre o espaço da página dupla. Esses "pequenos mundos" correspondem a espaços fechados, informados por elementos que dialogam entre si, dentro de uma realidade especificada pelo que está exposto.

A disposição das imagens em cada placa do Mnemosyne dá-se por meio de um elo temático que interliga as figuras ali expostas. No entanto, o seu sentido dependerá do olhante que se colocar à sua frente, bem como dos graus de relevância e destaque dados a cada uma das imagens. Essas disposições, posicionamentos e determinados ângulos, detalhes em exposição, criam um efeito de transição no olhar, que leva de uma figura à outra, gerando sentidos diversos a cada olhada em sequências diferentes. Esse efeito de transição no olhar resulta em movimento daquilo que está exposto, exatamente por mostrar uma miríade de interpretações dispostas dentro de um único espaço preto preenchido por recortes específicos.

Esta maneira de "contar" escolhida por Warburg, mostrando a história da arte, foi ímpar para os estudos, hoje consagrados, da relação palavra-imagem no campo da teoria visual. Segundo Philippe-Alain Michaud (2013, p. 132), referindo-se à relação mencionada anteriormente dentro do trabalho warburgiano:

\begin{abstract}
Nos estudos publicados por Warburg [...], os fenômenos de encadeamento não se dão apenas entre as imagens, mas também entre as imagens e os textos e no interior dos textos. Em virtude da importância atribuída à reprodução fotográfica das obras, a própria colocação na página assume uma significação singular em relação às leis tradicionais da comunicação erudita. A folha impressa, por analogia com o quadro, parece ser considerada como um plano. O texto não é mais um meio sem consistência, destinado à transmissão do sentido, mas é pensado inclusive em sua disposição espacial.
\end{abstract}

A disposição das linguagens verbal e visual, em caráter mais utilitarista, era uma "escolha segura" àqueles que primeiro produziram livros ilustrados para o público infantil - sendo que muitos escritores e ilustradores, na contemporaneidade, ainda se utilizam desta "fórmula pronta" na produção de novos títulos. Quando falamos dessa "fórmula pronta", remetemos ao que o filósofo e crítico literário Walter Benjamin escreveu em um de seus textos sobre os livros infantis, onde argumenta: "Ao lado da cartilha e do catecismo, também a enciclopédia ilustrada, o vocabulário ilustrado, ou como se queira chamar o Orbis pictus de Amos Comenius, encontra-se nas origens do livro infantil" (BENJAMIN, 2002, p. 55). O papel dado às ilustrações, fotografias e quaisquer outras imagens dispostas em livros infantis com maior enfoque na narrativa histórica, linear, contínua, não é o mesmo dado às imagens que compõem uma narrativa pictórica, não-linear, descontínua.

Nos livros ilustrados, as figuras que aparecem como um elemento auxiliar do texto escrito também carregam um aspecto de movimento, porém, trata-se de um movimento distinto daqueles que Aby Warburg e Suzy Lee colocam à disposição de seus olhantes - ou como queiramos chamar o leitor de imagens plásticas.

Segundo a especialista em livros infantis Sophie Van der Linden (2011, p. 104), o chamado "instante movimento", frequentemente usado nos livros ilustrados, figura um instante característico de uma ação completa, sugerindo um encadeamento breve na narrativa e, quase sempre, escolhido entre os momentos de maior movimentação descritos pelo texto verbal ao longo da estória.

Enquanto isso, os ditos "fenômenos de transição" - elementos que enaltecem o caráter de passagem, de transição nas imagens estáticas, bem como de uma imagem à 
outra - que Aby Warburg tanto exaltou em seu "atlas de imagens", e dos quais Suzy Lee se utiliza em seu livro-imagem, produzem efeitos de um movimento longe de ser instantâneo, contrário a um momento preciso e de curta duração.

Assim como os sentidos e interpretações variam de acordo com as sequências incontáveis que o olhar de um leitor/olhante faz ao fruir as placas do Mnemosyne, a narrativa pictórica de Espelho difere em muito dependendo do posicionamento que esse leitor/olhante se colocar diante do objeto livro - uma tomada de decisão, ética e estética, sobre qual lado representaria o mundo real ficcional (primeiro "cenário", onde se encontra a personagem) e qual representaria o mundo imaginário ficcional (segundo "cenário", onde encontramos o reflexo dessa personagem), temática esta abordada por Suzy Lee em toda sua produção literária.

As transições de uma placa à outra, de uma página à outra, que dão movimento ao que está diante dos olhos, ocorrem paralelamente a um processo de figurabilidade, ou seja, um "conjunto dos processos, não mais técnicos nem formais, porém simbólicos, mediante os quais o sujeito representado vem inscrever-se numa imagem" (MICHAUD, 2013, p. 34). Esta inscrição, este aparecimento, é ponto inicial para uma ação contrária à fixidez das imagens, à sua imobilidade. Em sucessão a esse aparecimento, o mesmo sujeito se finda em um processo de desaparecimento, mantendo o movimento.

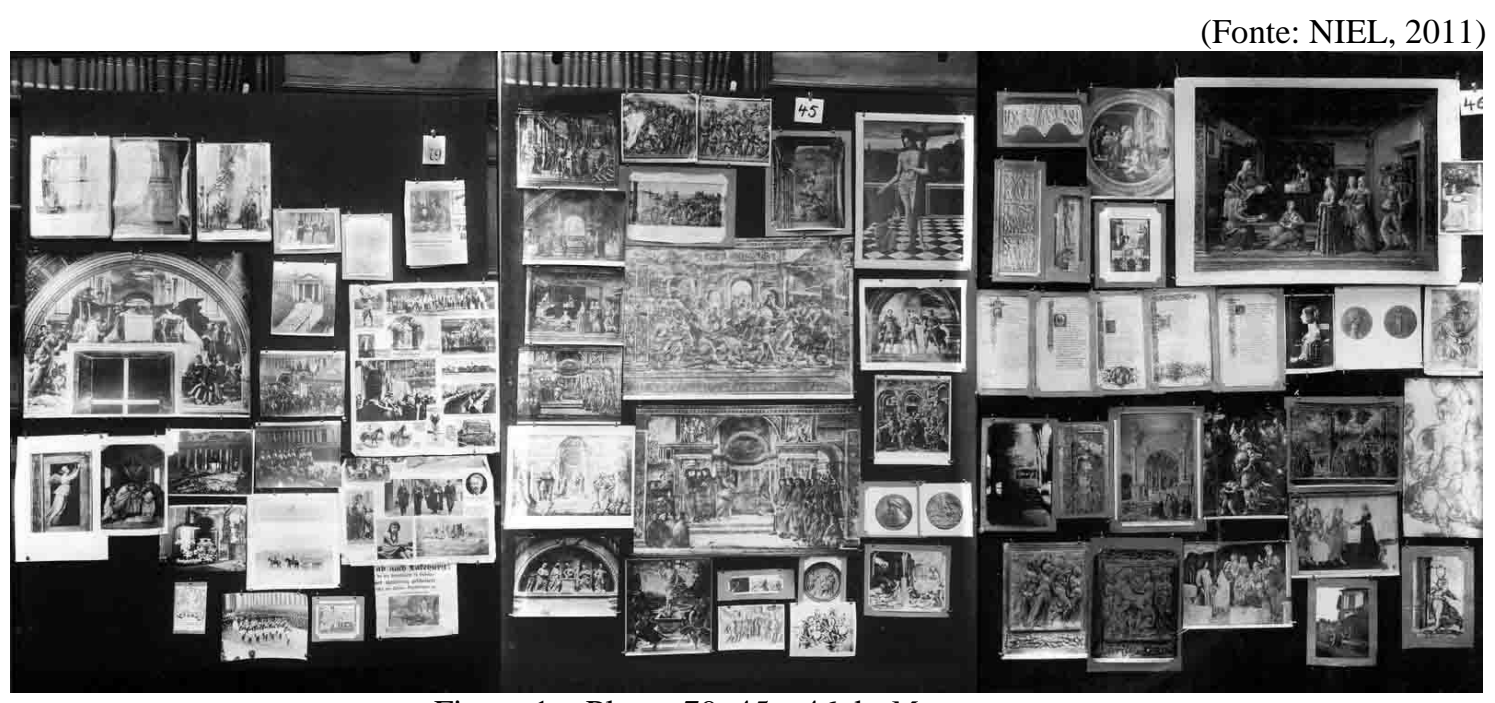

Figura 1 - Placas 79, 45 e 46 da Mnemosyne.

Enquanto em Mnemosyne as inscrições nas placas de fundo preto se dão por meio de recortes de textos, fotografias e ilustrações - onde cada placa é um "pequeno mundo" contextualizado por seu conteúdo, sem tema especificado em uma legenda; em Espelho, essa inscrição é produzida pela presença solo nas páginas duplas de uma personagem ilustrada em carvão, bem como pela aparição complementar de pontos coloridos em amarelo e preto, além de um fundo escuro que aparece, próximo ao fim da estória, por trás do que se entende como espelho. Tudo em movimento constante, ainda que pontual, acontecendo com a ação temporal de um "virar de página" por parte do leitor/olhante - dentro de uma narrativa pictórica composta por vários "pequenos mundos". Estruturas estáticas em movimento pelos efeitos entre suas inscrições visuais. 


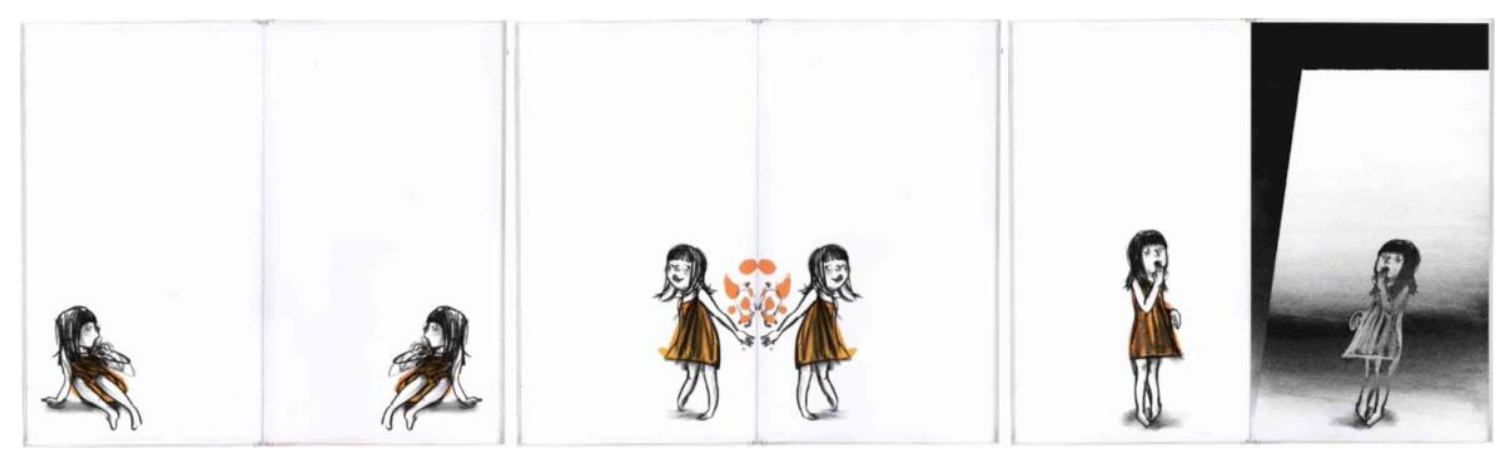

Figura 2 - Processos de figurabilidade em Espelho.

Contendo um total de 48 páginas preenchidas por 28 ilustrações e nenhuma palavra, além do título impresso na capa, Espelho é "dividido" em sequências de páginas duplas encadernadas em um livro no formato retangular vertical, tradicional de espelhos, que Suzy Lee (2013) remete diretamente com o "estágio de espelho", do psicanalista francês Jacques Lacan, como estudo visitado sobre o espaço imaginário de uma criança. Cada uma dessas sequências é como um "ato" teatral que a ilustração de uma garotinha protagoniza em movimento pelo palco, completamente destituído de fundo, representado pelo branco das páginas duplas - espaço este onde se dá o processo de figurabilidade nesta narrativa pictórica.

Em paralelo ao pensamento de Walter Benjamin, quando esse argumenta que "saber orientar-se numa cidade não significa muito", quando, na realidade, o mais difícil seria "perder-se numa cidade, como alguém se perde numa floresta" (BENJAMIN, 1987, p. 73), a ambientação visual que a autora produz é ideal para que o leitor/olhante "possa perder o fio da história sem a ajuda das palavras" (LEE, 2012, p. 146), assim como qualquer leitor/olhante que se posicione em frente a uma pintura e a admire, como quem vê uma fotografia.

Por sua vez, listadas unicamente por uma numeração (Fig. 1), as placas elaboradas por Aby Warburg são constituídas por imagens que "só manifestam sua significação expressiva sob a condição de serem tomadas numa disposição de encadeamento" (MICHAUD, 2013, p. 300). Semelhante ao que ocorria com o cinema nascente do século XIX, o sistema de montagem generalizada do Mnemosyne era inteiramente sustentado pela "estética do movimento" (MICHAUD, 2013, p. 40), tal como acontece nas sequências das páginas duplas em Espelho. A própria Suzy Lee compara seu livro com um filme, ao dizer: "Quando trabalho, às vezes é como se eu estivesse desenhando fotogramas de um filme de animação" (LEE, 2012, p. 148), o que associaria, assim, sua produção à crença animista que também sustenta as placas componentes do atlas do historiador alemão.

\section{2 (Des)aparição: dinamicidade em meio à estaticidade}

Dentre as várias sequências de Espelho, destacam-se exatos três momentos onde o processo de figurabilidade se dá de uma maneira mais abrupta e clara, são eles: a primeira aparição do reflexo na extremidade da página oposta à da primeira ilustração apresentada na narrativa; os primeiros pontos em amarelo e preto que emanam da 
margem central do livro - este "terceiro cenário"; e o fundo escuro que se mostra quando a representação do espelho é empurrada (Fig. 2).

$\mathrm{O}$ primeiro processo de figurabilidade acontece com o aparecimento de uma mesma ilustração surpresa nos extremos de uma página dupla. Essa ilustração, que irrompe após uma "virada de página", faz desaparecer a primeira página dupla da estória - esta preenchida apenas em sua extremidade direita por uma garota sentada em aspecto solitário.

Este aparecimento de um reflexo, idêntico, nas extremidades da esquerda e da direita, nos faz entrar no movimento criado pela surpresa dessas duas páginas como reação à estática página dupla anterior. Após este "ato" de surpresa, há um período de re-conhecimento das extremidades como reflexos perfeitos uma da outra, tudo com um aspecto de curiosidade, mistério e novidade. $\mathrm{O}$ que era estático começa a se dinamizar.

A figurabilidade que se faz presente no segundo momento traz à tona a importância da margem central do livro para o desenvolvimento da estória, pois os pontos em amarelo e preto aparecem como que emanando da dobra física, este "terceiro cenário" presente na página dupla. Esse é também o primeiro momento no qual as duas extremidades se aproximam e, de fato, dão início a uma interação mútua, já segura de seu re-conhecimento e não mais tão surpresa com a sua presença repentina.

Agora, não há apenas o movimento criado pela interação das ilustrações, como também o movimento de invasão dos pontos amarelo e preto no espaço da dupla aberta. Neste instante, as páginas duplas aparecem com um aspecto de diversão, o que exclui/deixa para trás as páginas duplas de fundo completamente branco, sem pinturas em amarelo e preto, de um aspecto tenso entre as extremidades. Dinâmica intensa.

Chegamos ao terceiro momento onde se identifica um processo de figurabilidade com o aparecimento de um fundo escuro, até agora escondido, no mundo habitado pelo suposto reflexo da personagem, o qual se faz presente no "segundo cenário". Esse momento é posterior ao aparecimento e desaparecimento das páginas duplas completamente em branco, que representam a total entrada dessas personagens no "terceiro cenário" da narrativa; é também resultado dos movimentos gerados pela não mais cumplicidade entre a garotinha e seu reflexo - ambos saídos da margem central do livro sem mais seguir as "regras" de simetria e semelhança de um espelho.

Neste momento, também, já não vemos mais os pontos amarelo e preto que anteriormente invadiam as páginas duplas, nem símbolos claros de qual extremidade é a "original" e qual é o reflexo devido à discordância de suas ações e reações, do caráter de desagrado causado por essa desarmonia/disparidade. Dinamicidade em ápice dramático.

A respeito deste aspecto interativo entre as duas extremidades nas páginas duplas de seu livro, Suzy Lee fala, durante uma conferência sobre livros-imagem, acerca das escolhas que fez na criação da narrativa pictórica ora analisada:

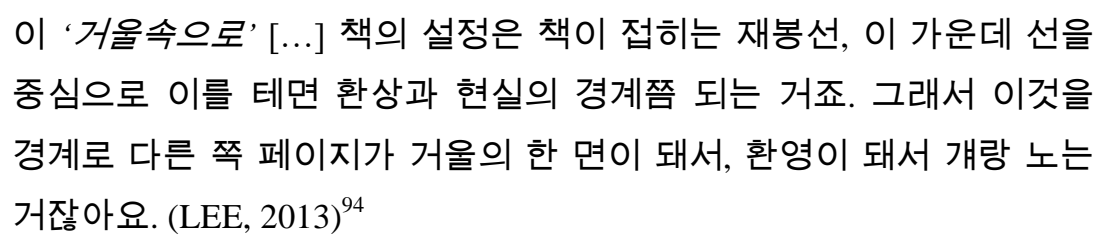
중심으로 이를 테면 환상과 현실의 경계쯤 되는 거죠. 그래서 이것을 경계로 다른 쪽 페이지가 거울의 한 면이 돼서, 환영이 돼서 개랑 노는 거잔아요. (LEE, 2013)

Além dos momentos de figurabilidade mencionados até aqui - diretamente ligados à criação de movimento na narrativa -, acontece um outro momento específico,

\footnotetext{
94 “'Em 'Espelho' [...] o ponto principal está no centro do livro, onde ele se dobra. Isto representaria um limite entre a realidade e a imaginação. Do outro lado desse limite, observa-se o lado oposto do espelho e assim as duas extremidades começam a brincar/interagir". (Tradução nossa)
} 
produto da utilização do título do livro como referente escrito, verbal, para a impressão, introdução de novos sentidos à estória. Tendo como base a palavra "espelho", o leitor/olhante se vê diante de páginas duplas que apresentam um ponto inicial e seu reflexo, da personagem que habita o "mundo real" ficcional e uma segunda personagem que habita o "mundo refletido".

No entanto, assim como muitas das placas que compõem o Mnemosyne, as páginas internas de Espelho não possuem texto verbal impresso, tornando a tarefa do leitor/olhante da narrativa pictórica algo próximo a do leitor/olhante de pinturas com legendas, pois a compreensão/elaboração da estória se dará dependendo da maneira como esse leitor/olhante se posiciona para ler/ver as linhas invisíveis nas imagens. Como bem refletiu o filósofo tcheco Vilém Flusser (2008, p. 185), a "imagem é 'melhor' que texto, por conter em superfície reduzida infinitas linhas", entrando em acordo com o pensamento de Suzy Lee (2012, p. 14) quando a mesma afirma que um dos motivos de ela gostar de trabalhar com livros-imagem é o fato de não ter que "pensar em colocar o texto" e poder se "concentrar somente na composição absoluta da figura". A justaposição dessas figuras em páginas cria uma narrativa repleta de significações e interpretações possíveis, independente do título impresso na capa do livro - impressão essa também considerada como imagem pela autora -, ainda mais se considerado seu sugestivo título em coreano: 거울속으로 ${ }^{95}$.

A exclusão, o desaparecimento de um momento na narrativa pictórica, consequência do "virar a página", é ponto final ao se tornar um novo ponto inicial, aparecimento de um novo momento, novo movimento. As páginas duplas que, no início, eram predominantemente brancas, dando assim um peso maior ao aparecimento das ilustrações, passam a dividir em seu quadrilátero elementos de sentido com os pontos coloridos vindos do "terceiro cenário", da dobra do livro, o que resulta em aspectos de movimento inéditos aos até então expostos pela obra.

Segundo Philippe-Alain Michaud (2013, p. 54), "a presença de um fundo monocromático atrás da figura destaca o próprio processo de figuração", o que vai de encontro ao imutável plano de fundo branco nas páginas de Espelho, enaltecendo o movimento de diálogo entre a personagem, o seu reflexo e o mundo imaginário que emana da margem central do livro. Além disso, esse mesmo fundo monocromático está presente nas placas de fundo preto do Mnemosyne, enaltecendo o caráter dialógico dos recortes de imagens e textos verbais dispostos em cada "pequeno mundo".

Tendo visto estas sequências com os processos de figurabilidade envolvendo tanto personagem e seu reflexo, seus momentos de aparecimento e desaparecimento resultantes das passagens de páginas, cabe-nos agora discutir para além do movimento presente nas páginas duplas do primeiro título componente da "Trilogia da Margem". Atingindo o momento de desaparecimento de todas as personagens visíveis desta narrativa pictórica, composta por duas páginas completamente em branco, "vazias", caminhamos em paralelo com o que Philippe-Alain Michaud escreveu a respeito da obra de Aby Warburg, onde diz: "A representação do movimento não mais pretendia sugerir a circulação de corpos móveis no espaço, mas sua presença na imagem; não o seu deslocamento, mas sua presença" (MICHAUD, 2013, p. 99).

Referindo-se à presença de páginas em branco, "vazias" em seus livros, Suzy Lee pontua (2012, p. 112): "Uma página vazia sem contexto pode ser um erro de impressão, mas se o branco da página é essencial para adicionar sentido ao contexto, uma página sem palavras ou imagens não é uma página vazia". Tal reflexão entra em sintonia com o que o poeta francês Stéphane Mallarmé aponta, referindo-se à presença

\footnotetext{
${ }^{95}$ Traduzindo diretamente do coreano para o português, ficaria Dentro do espelho.
} 
de espaços "brancos" no poema-livro Un coup de dés jamais n'abolira le hasard (1987), como um "espaçamento da leitura", um "silêncio em derredor", uma "cenografia espiritual" (apud CAMPOS, A.; CAMPOS, H.; PIGNATARI, 2013, p. 151) na obra.

\section{Sintomas de presença no vazio}

A existência de páginas completamente em branco, "vazias", na construção de Espelho é fator instigante, uma vez que essas mesmas páginas possuem seu peso dentro da narrativa pictórica, sua característica determinante para a impressão/produção de sentido à estória - resultante da "produção de presença" que as mesmas incitam.

Ao "trazer para diante" do leitor o que está presente em seu "vazio", as páginas brancas deste livro de Suzy Lee entram em harmonia com a expressão que o teórico alemão Hans Ulrich Gumbrecht (2010, p. 38-39) aponta como um "efeito de tangibilidade" espacial - a impressão de que algo que está "presente" à nossa frente esteja também ao nosso alcance, seja tangível -, estando em permanente movimento "de maior ou menor aproximação e de maior ou menor intensidade". O tal espaço em "branco", esta "trama de ausência e de vazio" (MALLARMÉ apud BLANCHOT, 2013, p. 81), o palco da estória, é ambiente referencial para os processos de figurabilidade discutidos anteriormente, onde ocorrem os movimentos de aparecimento $\mathrm{e}$ desaparecimento, onde todos os elementos da narrativa surgem e se ausentam estando presentes, não deixando de estar "ao alcance" de seu leitor/olhante.

(Fonte: LEE, 2009)

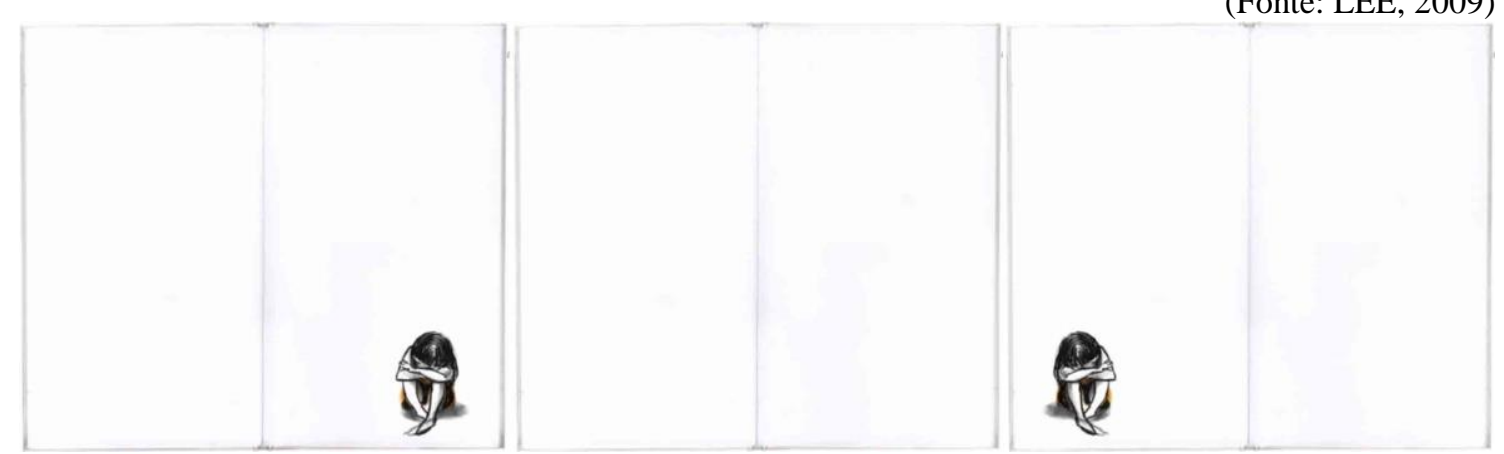

Figura 3 - Sintomas de presença no vazio em Espelho.

Assim como as quatro páginas em branco (Fig. 3) - uma na extremidade esquerda da primeira página dupla; duas na página dupla em seu meado; e uma na extremidade direita da página dupla final do livro -, a margem central de Espelho é também ambiente onde se desenrola um movimento constante, mesmo simultâneo, no qual uma estória paralela à exibida, ilustrada, pintada, acontece, tanto que este "terceiro cenário", a dobra, desempenha papel de "protagonista" das páginas "vazias".

Segundo o autor e crítico de literatura infantil Perry Nodelman (1988), a presença de uma imagem plástica em uma narrativa faz mais do que meramente pontuar sua existência, o que vai de acordo ao pensamento de Suzy Lee com relação à utilização destas páginas "vazias" para produzir presença e, como consequência, sentido em seu livro. A autora diz:

Os efeitos de uma página vazia são bem dramáticos. Quando a criança desaparece totalmente em Espelho, os leitores se defrontam com um silêncio repentino. A página vazia insinua a próxima reviravolta ao fornecer, ao mesmo tempo, um respiro para a história de ritmo rápido. É o equivalente a quando as luzes se apagam no cinema ou no teatro. Não ficamos curiosos 
para saber o que acontecerá quando as luzes forem acesas novamente? (LEE, 2012, p. 114)

Esta ação de apagar as luzes do palco, fazendo as ilustrações da personagem e seu reflexo desaparecerem dos "cenários" visíveis para o leitor/olhante, deixa para trás um resquício de movimento, o qual continua presente na página "vazia", pois o texto visual deixou o palco ao adentrar na margem central do objeto livro. Este ambiente que se fez presente rapidamente atraiu olhares e logo saiu de cena, levando consigo todo o elenco como uma cortina que se fecha, um refletor que se apaga. O leitor/olhante permanece na sua posição, aguardando pelo próximo "ato", que só terá lugar ao movimento de um "virar de página". Dinâmica efetuada por esse leitor/olhante.

A "reviravolta" que Suzy Lee menciona é outro sintoma da presença que emana da página dupla em branco. As extremidades, que anteriormente estavam em harmonia nos seus movimentos, agora "atuam" individualmente, sem qualquer traço de similaridade, de reflexo. O que terá acontecido neste "terceiro cenário"? O que desencadeou a desarmonia da personagem e seu reflexo? Tais indagações, sem respostas dadas pela autora, apenas reafirmam a presença na ausência das páginas "vazias", espaço que é lugar de movimentos invisíveis ao olhar do leitor/olhante e à produção de sentido na narrativa. No entanto, apesar de se fazer presente ao longo dos quadriláteros que compõem o livro, ele está de passagem, em uma constância.

Gumbrecht (2010, p. 135) reformula o argumento do filósofo francês Jean-Luc Nancy $^{96}$ sobre o movimento duplo de um "nascimento para a presença" e de um "desaparecer da presença" quando diz que os fenômenos de presença não podem deixar de ser efêmeros, o que serve de alicerce complementar à presença das quatro páginas em branco em Espelho: todas em ambientes passageiros, todas enaltecendo os movimentos de aparecimento e desaparecimento, todas informando uma presença ausente e cercada por "nuvens" de sentido.

Enquanto a página dupla inicial da narrativa, composta por uma extremidade em branco à esquerda e uma extremidade contendo uma ilustração à direita, traz à tona uma produção de presença por meio de um movimento de aparecimento, o título deste livro de Suzy Lee, em língua portuguesa, "perde" um pouco do seu sentido após a passagem da página dupla em branco - diferentemente do que acontece com a utilização do título em língua coreana. As mudanças comportamentais das personagens após esta imersão na margem central são nítidas, especialmente por já não expor o aspecto mimético de reflexo do espelho, mas movimentos distintos.

As figuras que emanam/saem da margem central do livro não podem mais ser apontadas como personagem e seu reflexo, pois os sintomas para a produção de sentido que deveriam estar presentes na imagem à mostra para o leitor/olhante já não vingam, não expressam mais os sentimentos que esse mesmo leitor conseguia expressar em palavras (NIKOLAJEVA \& SCOTT, 2011) até pouco antes dessa passagem pelo espaço "vazio".

A característica de reflexo é retomada na página dupla final do livro, onde a extremidade impressa com uma ilustração à esquerda é seguida por uma extremidade completamente em branco à direita - espelhamento da primeira página dupla da narrativa -, resultante de um movimento de desaparecimento da presença. Tal ponto reafirma o caráter efêmero dos fenômenos de presença anteriormente expostos.

\footnotetext{
${ }^{96}$ Argumento este feito no livro The Birth to Presence, lançado pela Standford University Press em 1993, onde Jean-Luc Nancy observa que "os efeitos de presença que podemos viver já estão sempre permeados pela ausência” (apud GUMBRECHT, 2010, p. 135).
} 
No que concerne à concepção de "presença real", Jean-Luc Nancy (apud GUMBRECHT, 2010, p. 82) foi o primeiro a apontar para a certeza de que a presença não pode passar a fazer parte de uma situação permanente, e que, apesar de seu "efeito de tangibilidade" espacial, nunca pode ser uma coisa a que nós possamos agarrar. E, seguindo este raciocínio, torna-se plausível a nossa incapacidade de ter acesso ao que ocorre no palco do "terceiro cenário" em Espelho, este espaço tangível, porém invisível, cuja presença se dá na ausência de qualquer sintoma de sentido que se ponha diante dos olhos de quem acompanha o desenrolar da narrativa pictórica. Isto também responde às indagações levantadas sobre o que acontece no espaço da margem central.

Os sintomas de presença ainda tomam lugar em um dos pontos que mais intriga os leitores/olhantes deste livro-imagem de Suzy Lee: afinal, quem é a personagem e quem é o reflexo? Quando nos colocamos diante da primeira página dupla do livro, vemos uma figura ilustrando a extremidade direita do quadrilátero - com a extremidade esquerda completamente em branco -, sendo que na sequência, com o "virar de página", o movimento de aparecimento que teve início se dá com a simultaneidade de presença das figuras nas duas extremidades. A partir deste momento, podemos apontar tanto a extremidade esquerda, a qual apareceu, quanto a extremidade direita, a qual já existia, como personagem e/ou seu reflexo.

Com a reviravolta ocorrida nas páginas duplas vazias, presenciamos uma iniciativa tomada pela extremidade esquerda com relação à discordância da extremidade direita em seguir sua função de reflexo. Após o ato último de reação por parte da extremidade esquerda, acabamos diante de um espelho quebrado, que vai desaparecendo na extremidade direita, o que nos leva à página dupla final, onde ficamos diante da extremidade esquerda impressa em movimento de reflexo à extremidade direita na primeira página dupla da obra. Os espaços "vazios" que aparecem na extremidade esquerda no início e na extremidade direita ao final de Espelho remetem-nos à pura pulsação de aparecer e desaparecer sobre a qual Philippe-Alain Michaud (2013) comenta com relação à Dança dos búfalos - "efígie fílmica" produzida por William Kennedy-Laurie Dickson no seu estúdio Black Maria em 1894.

Assim como o conceito de ação - "dentro de uma cultura de sentido" vinculado ao ritual de dança dos índios americanos se aproxima do conceito de magia "dentro de uma cultura de presença" (GUMBRECHT, 2010, p. 109) -, o papel da página dupla "vazia" neste livro da book artist sul-coreana é desencadeador de um movimento de dança ilustrado pela personagem e seu, não mais, reflexo.

Dançando individualmente, cada uma em seu "cenário", realizando "atos" diferentes em palcos "vizinhos", elas produzem presença em cada uma das páginas duplas enquanto a ação é meramente desenvolvida sem a produção de sentido. $O$ "despertar" da extremidade esquerda para o fato de a extremidade direita não mais seguir os seus "passos" dá início a uma série de ações e reações, desacordos, negações, tudo culminando no ato de a extremidade esquerda "empurrar" seu suposto reflexo na extremidade direita, dando fim à assimetria que se instalou após a saída de ambas as extremidades da margem central do livro. É então que se dá o acontecimento, o aparecimento do fundo escuro na extremidade direita da página dupla.

Este rápido aparecimento de uma profundidade escura na página, que não demora a se tornar completamente branca, "traz à tona" para o leitor/olhante mais um sintoma de presença nas páginas vazias que compõem a narrativa de Espelho. Este rápido acontecimento em um movimento duplo de aparição e ocultação caminha próximo ao que o filósofo alemão Martin Heidegger conceitua como Ser, que é "aquilo que ao mesmo tempo se revela e se oculta no acontecimento da verdade" (apud GUMBRECHT, 2010, p. 93), de forma passageira, não permanente. 


\section{Considerações finais}

Estes movimentos de aparecer e desaparecer, que impõem a efêmera presença nas páginas "vazias" da narrativa pictórica aqui visitada, bem como nas placas pretas do "atlas de imagens" warburgiano, repetem-se constantemente com as inúmeras "viradas de páginas" realizadas desde a abertura do objeto livro à contemplação de sua contracapa - quando mesmo da fruição dos recortes de imagens e textos expostos em cada placa do Mnemosyne.

O efeito repetitivo que "traz à tona" um quadrilátero informado com páginas "vazias" e mesmo impressas com figuras ilustradas, além dos encadeamentos de imagens na placas pretas de um atlas que "conta" pictoricamente a história da arte, rememoram também o tradicional teatro $N \hat{o}$, do Japão, onde "os corpos dos atores parecem ganhar forma e presença à medida que vem para diante do pano de palco e chegam à boca de cena numa longa sequência, quase infinita, de movimentos para trás e para diante" (GUMBRECHT, 2010, p. 184).

$\mathrm{Na}$ raiz oriental pela qual Hans Ulrich Gumbrecht (2010) caminhou para refletir acerca de sua teoria da "produção de presença" - mesma que estrutura a cultura de Suzy Lee -, Aby Warburg se interessou pelo miê, uma possível tradução em japonês para Pathosformel. O teórico cultural alemão se interessou pelo "movimento cristalizado no instante de sua suprema intensidade", para assim procurar "justapor figuras no ponto culminante de sua expressividade", colecionando assim as Pathosformel no Mnemosyne (MICHAUD, 2013, p. 312).

Com o livro-imagem, vale "colocar à frente" de um leitor/olhante o fato de que todo esse movimento de figurabilidade, intensidade e expressividade se dá em um espaço que "não é nada além de que um pedaço de papel” (LEE, 2012, p. 114). A presença se faz em resultado ao aparecimento e desaparecimento, diretamente ligados ao "virar de página", ao ir e voltar do olhar "de uma imagem à outra" dentro de um "pequeno mundo" representado por folhas em uma página dupla, ou mesmo por uma placa preta enumerada e com temática definida pelos recortes em exposição.

\section{REFERÊNCIAS}

BENJAMIN, Walter. Obras escolhidas vol. 2: Rua de mão única. Trad. Rubens R. T. Filho e José C. M. Barbosa. São Paulo: Editora Brasiliense, 1987. . Reflexões sobre a criança, o brinquedo e a educação. Trad. Marcus Vinicius

Mazzari. São Paulo: Duas Cidades; Editora 34, 2002.

BLANCHOT, Maurice. O livro por vir. Tradução de Leyla Perrone-Moisés. 2a ed. São Paulo: Editora WMF Martins Fontes, 2013.

CAMPOS, Augusto; CAMPOS, Haroldo; PIGNATARI, Décio. Mallarmé. 4a ed. São Paulo: Perspectiva, 2013.

FLUSSER, Vilém. O universo das imagens técnicas: elogio da superficialidade. São Paulo: Annablume, 2008.

GUMBRECHT, Hans Ulrich. Produção de presença: o que o sentido não consegue transmitir. Tradução de Ana I, Soares. Rio de Janeiro: Contraponto; Ed. PUC-Rio, 2010.

LEE, Suzy. Espelho. São Paulo: Cosac Naify, 2009.

. A trilogia da margem: o livro-imagem segundo Suzy Lee. Tradução de Cid

Knipel. São Paulo: Cosac Naify, 2012. 
어른, 그림책을 보다. C!Talk Seoul 2회. WCO_C!talk. Atualizado em 27 jun. 2013. Disponível em: <https://www.youtube.com/watch?v=d6hK1Mk3zyU>. Acesso em: 20 jul. 2015.

LINDEN, Sophie V. D. Para ler o livro ilustrado. Tradução de Dorothée de Bruchard. São Paulo: Cosac Naify, 2011.

MICHAUD, Philippe-Alain. Aby Warburg e a imagem em movimento. Tradução de Vera Ribeiro. Rio de Janeiro: Contraponto, 2013.

NIEL, Leone. Atlas Mnemosine. A regra e a excepção. Atualizado em 08 dez. 2011. Disponível em: <http://aregraeaexcepcao.blogspot.com.br/2011/12/atlasmnemosine.html>. Acesso em: 20 jul. 2015.

NIKOLAJEVA, Maria; SCOTT, Carole. Livro ilustrado: palavras e imagens. Tradução de Cid Knipel. São Paulo: Cosac Naify, 2011.

NODELMAN, Perry. Words about pictures: the narrative art of children's picture books. Athens: UGA Press, 1988. 